\title{
BMJ Open Sick and still at school: an empirical study of sickness presence among students in Norwegian secondary school
}

\author{
Vegard Johansen
}

To cite: Johansen V. Sick and still at school: an empirical study of sickness presence among students in Norwegian secondary school. BMJ Open 2015;5:e008290. doi:10.1136/bmjopen-2015008290

- Prepublication history for this paper is available online. To view these files please visit the journal online (http://dx.doi.org/10.1136/ bmjopen-2015-008290).

Received 23 March 2015 Revised 4 August 2015 Accepted 14 August 2015

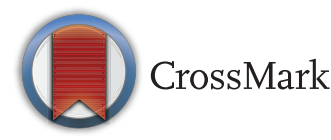

Eastern Norway Research Institute/Norwegian University of Science and Technology, Trondheim, Norway

Correspondence to Dr Vegard Johansen; vj@ostforsk.no

\section{ABSTRACT}

Objectives: This paper investigates sickness presence (SP) among students. The research questions asked are: What is the distribution of SP among students in Norwegian secondary school? What characterises students with high SP in Norwegian secondary schools?

Design: A cross-sectional survey conducted in 10th grade in lower secondary school (LSS) and level 2 in upper secondary school (USS). The study was conducted using multivariate binomial logistic regression analysis.

Participants: The survey was administered to 66 schools, and 2 or 3 classes participated at each school. The response rate was $84 \%$ in LSS $(n=1880)$ and $81 \%$ in USS ( $\mathrm{n}=1160)$.

Primary and secondary outcome measures: The paper provides information about the distribution of SP in secondary schools. The paper also examines which factors influence high SP.

Results: $75 \%$ of students in LSS and $80 \%$ of students in USS reported SP in the previous school year. $24 \%$ of students in LSS and $33 \%$ of students in USS reported high SP (4 episodes or more). Students with high absence from school were more likely to report high SP (ORLSS=1.7, ORUSS=2.0) than those with low/no absence. Girls were more likely to report high SP (ORLSS $=1.5$, ORUSS $=1.5$ ) than boys. In LSS, students with high school motivation reported high SP more often than students with low/medium motivation. In USS, students in vocational studies programmes reported high SP more often than students in general/ academic studies programmes.

Conclusions: Some SP during a school year may be more common than no SP. Gender, absence, motivation and education programme were important factors for high SP in secondary school.

\section{INTRODUCTION}

Sickness presence (SP) refers to going to work despite illness, and the concept has been a subject of increasing interest in the past two decades. ${ }^{1-5}$ Previous studies in different countries have investigated SP among different occupational groups. ${ }^{6-19}$ Several studies have shown that the majority of

\section{Strengths and limitations of this study}

- The sample was quite large (3120 students from 15 to 18 years of age).

- The response rate was high ( $84 \%$ in lower secondary school and $81 \%$ in upper secondary school).

- The responses to questions about sickness presence may suffer from recall bias and response bias.

workers go to work when they ought to stay at home for health reasons. More than $80 \%$ of general practitioners, hospital physicians and senior accountants reported SP in a British study, ${ }^{6}$ and a similar proportion of SP was reported in a Norwegian study of physicians. $^{7}$ More than $70 \%$ of the Danish core work force reported $\mathrm{SP}^{8}$ and the same share reported SP in a study of a Canadian public service organisation. ${ }^{9}$ About $60 \%$ of national samples of workers in the Netherlands, Sweden and Norway reported one or more episodes of SP in a year. ${ }^{10} 11$

(North) European research has concentrated on the association between health, sickness absence and SP. One main finding from cross-sectional studies is that the association between sickness absence and SP is strongly positive. ${ }^{1}{ }^{3}{ }^{4}$ Longitudinal studies have shown that several episodes of SP can cause serious health problems at a later stage, and high SP is also a risk factor for future (long-term) sickness absence. ${ }^{12-16}$

American research has investigated the consequences of SP on the productivity of organisations. SP reduces work capacity and could influence the quality and quantity of the work performed by personnel with SP. There is also the risk that those practising SP could infect colleagues. Consequently, such studies argue that managing SP effectively could be a competitive advantage. ${ }^{2}$ 17-19

There are also studies investigating determinants of SP. Personal factors found to have 
an impact on SP include self-rated health status, education level, age, economic situation, social support, state of work-life balance and latitude in decision-making. The work-related factors found to influence SP include occupational affiliation, employment in the public or private sector, job security/insecurity, work burden, working-time arrangements, workplace culture, job satisfaction, control over work tasks and potential for adjusting work demands. ${ }^{1-3} 67111619$ A study in Norway and Sweden found that the most frequently reported reasons for SP include 'not burden colleagues', 'enjoy work' and 'feeling indispensable'. ${ }^{11}$

While there are several studies of SP among workers, no study has investigated the prevalence of SP among students in secondary schools. Still, there are some good reasons to expand the body of work on SP to also include students in secondary schools. One reason for investigating SP in secondary schools is that experiencing several episodes of SP during the school year could be a possible indicator for future ill health. This is similar to previous studies among workers who have shown that SP in the workplace may be predictive of future ill health. ${ }^{12-16}$ Another reason is that SP could reduce the capacity for work at school, and also negatively influence the quality of work performed at school. This is similar to previous studies among workers who have shown that SP reduces work capacity. ${ }^{2}{ }^{17-19}$ A third reason is that attitudes are relatively consistent over time, and it is possible that attitudes towards absence and presence are something that might follow young people from school to the workplace. ${ }^{20-22}$

This paper will show the distribution of SP in lower secondary school (LSS) and upper secondary school (USS). In addition, the paper uncovers relevant determinants for high SP in secondary school. Using data from a study with 3120 students in Norwegian secondary school, this study poses two research questions: What is the distribution of SP among students in Norwegian secondary school? What characterises students with high SP in Norwegian secondary schools?

\section{METHODS}

The data used are from a student survey conducted in Norwegian secondary school at the end of the school year in 2012. The participants in the survey included students in 10th grade in LSS (15-16 years) and students in level 2 in USS (17-18 years). The data collection was part of a research project for the Ministry of Education and Training, Ministry of Trade, Industry and Fisheries, and Ministry of Local Government and Modernisation. The Ministries had no role in study design; in the collection, analysis and interpretation of the data; in the writing of the paper; or in the decision to submit for publication.

The survey was administered to 66 schools, and it included 36 LSSs and 30 USSs. The principals of the schools had participated in a former survey about the topics of this survey. Compared with the population of secondary schools in Norway, the selected schools were representative with regard to school size, centrality/peripherality, academic performance, ethnicity and education programmes (only USS).

At each school, two or three classes participated, and each school appointed a contact person who was responsible for distributing the surveys to the classes. Questionnaires were completed in writing at school. The response rate was $84 \%$ in 10th grade in LSS and $81 \%$ in level 2 in USS. In total, 2230 students in LSS were asked to participate in the survey and 1880 responded, and 1440 students in USS were asked to participate and 1160 responded.

The questionnaire was designed specifically for this research project. It included questions about school performance, generic skills, entrepreneurial skills, school motivation and effort, school absence, SP, and some background variables. A pilot study was conducted to ensure that young respondents (15-18 years of age) understood all of the questions. The respondents used about 15-20 min to fill out the questionnaire.

The information letter was provided to students, parents and teachers. It explained the purpose of the study (to investigate self-reported skills, motivation, absence and presence), and that it was voluntary to answer the survey. It also included contact information for the project leader, including email address and telephone number. Students who decided not to answer the survey did other school work.

All respondents were anonymous to the research team. Direct personal data were not collected, and none of the respondents could be identified through a combination of background information since few background variables were requested.

Frequency of SP (the distribution of SP episodes) was measured by the following question: 'During the last school year, did you go to school despite feeling so ill that you should have taken sick leave?'. The respondents were presented with four alternatives: 'No'; 'Yes, one time'; 'Yes, two to three times'; 'Yes, four times or more'. The total length of SP (in days) was measured by this question: 'Please estimate how many days you went to school when you were feeling so ill that you should have taken sick leave during the last school year'. The respondents were presented with five alternatives: 'None', '1-7 days', '8-14 days', '15-30 days', '31 days or more'.

Binomial logistic regression was used to detect which factors influence high SP (four episodes or more). Binomial logistic regression is suitable for predicting the outcome of a categorical criterion variable that can take on only two possible outcomes. ${ }^{23}$ The regression analyses in the Results section include eight independent variables. Some of them corresponded with studies about factors influencing SP in the adult population (gender, migratory status, parents' education and absence from school),${ }^{1-4} 8-11$ while other factors were unique for secondary school students (parents' 
employment status, school performance, school motivation and education programme):

- Gender: Divided between male (reference category) and female.

- Migratory status: Divided between natives (reference category) and immigrants (comprising students born in other countries or both parents born in other countries).

- Parents' education: Divided between students who have parents with low educational attainment (reference category) and students who have parents with high educational attainment (Bachelor degree or higher).

- Parents' employment status: Divided between students who have both parents who are working (reference category), and students who have one or both parents who are not working. In the case of students with only one living parent, the division is whether this parent works or not.

- Absence from school: Divided between students reporting low or no absence (reference category) and students reporting high absence from school (four or more absence episodes).

- School performance: Norwegian grades range from 1 (lowest) to 6 (highest) and are standardised measurements of varying levels of comprehension within a subject area. The indicator for school performance is the grade point average (GPA), and it is calculated by adding the grade points a student earns and then dividing the sum by the total number of subjects taken.

- School motivation: A scale variable ranging from 1 (high motivation) to 5 (low motivation) was used. This is a standardised index and based on three variables measuring the general interest in school, whether the student likes to do school work, and whether the student considers what he or she learns in school to be meaningful/useful. Internal reliability is good (Cronbach's $\alpha$ was 0.82 in LSS and 0.82 in USS), and the index is also used in the annual student survey in Norway. ${ }^{24}$

- Education programme: This dimension is only relevant for USS, and it is divided between general studies (reference category) and vocational studies. A vocational studies programme generally leads to a craft or journeyman's certificate, usually after 2 years in school and 1 year of in-service training in an enterprise. A general studies programme takes 3 years and leads to general university admission certification.

\section{RESULTS}

The results section includes five tables. Table 1 presents descriptive statistics about the LSS and USS study populations. The students in LSS are 15-16 years of age and the students in USS are 17-18 years old. The study populations were representative with regard to the proportion of boys (52\% in LSS and 50\% in USS), proportion of natives (85\% in LSS and $88 \%$ in USS) and school
Table 1 Descriptive statistics of factors expected to influence high sickness presence in Norwegian secondary school, percentage of pupils or means

\begin{tabular}{lll}
\hline & $\begin{array}{l}\text { Lower } \\
\text { secondary } \\
\text { school (15 and } \\
\mathbf{1 6} \text { years) }\end{array}$ & $\begin{array}{l}\text { Upper } \\
\text { secondary } \\
\text { school (17 and } \\
\mathbf{1 8} \text { years) }\end{array}$ \\
\hline Boys & 52 & 50 \\
Natives & 85 & 88 \\
$\begin{array}{l}\text { Parents with low } \\
\text { education }\end{array}$ & 53 & 48 \\
$\begin{array}{l}\text { Working parents } \\
\text { No/low absence }\end{array}$ & 82 & 82 \\
from school & 75 & 62 \\
$\begin{array}{l}\text { School performance } \\
\text { (scale 1-6) }\end{array}$ & 3.9 & 3.9 \\
$\begin{array}{l}\text { School motivation } \\
\text { (scale 1-5) }\end{array}$ & 3.1 & 3.2 \\
General studies & NA & 61 \\
\hline NA, not available. & &
\end{tabular}

performance (mean GPA of 3.9). While the mean score for school motivation was the same for LSS and USS (3.2), there were more students with high absence from school in USS than LSS (38\% in USS and 25\% in LSS).

Table 2 displays information about the distribution of SP episodes. Seventy-five per cent of the respondents in LSS and $80 \%$ of respondents in USS replied that they had gone to school even though it would have been reasonable to take sick leave. Twenty-four per cent in LSS and $33 \%$ in USS reported four or more SP episodes.

Table 3 presents the length of SP. The majority (58\% of respondents in LSS and 59\% of respondents in USS) reported 1-7 days SP in the previous school year. Seventeen per cent in LSS and 21\% in USS reported 8 days or more SP.

Table 4 shows ORs and $\mathrm{p}$ values (*) from two multivariate logistic regression models of factors relevant to high SP. The results were adjusted for the other possible factors. In LSS, there were statistically significant associations $(p<0.05)$ for 'female', 'high absence from school' and 'school motivation'. In USS, there were statistically significant associations $(\mathrm{p}<0.05)$ for 'female', 'high absence from school' and 'vocational studies'. The

Table 2 Distribution of sickness presence episodes in Norwegian secondary school, percentage of pupils

\begin{tabular}{lcc}
\hline & $\begin{array}{l}\text { Lower secondary } \\
\text { school }(\mathbf{N = 1 8 4 1 )}\end{array}$ & $\begin{array}{l}\text { Upper secondary } \\
\text { school }(\mathbf{N = 1 1 4 8})\end{array}$ \\
\hline 0 episodes & 25 & 20 \\
$1-3$ episodes & 51 & 47 \\
4 or more & 24 & 33 \\
episodes & & \\
Sum & 100 & 100 \\
\hline
\end{tabular}


Table 3 Distribution of sickness presence days in Norwegian secondary school, percentage of pupils

\begin{tabular}{lcc}
\hline & $\begin{array}{c}\text { Lower secondary } \\
\text { school }(\mathbf{N = 1 8 4 1 )}\end{array}$ & $\begin{array}{l}\text { Upper secondary } \\
\text { school }(\mathrm{N}=1148)\end{array}$ \\
\hline 0 days & 25 & 20 \\
1-7 days & 58 & 59 \\
8-14 days & 12 & 13 \\
15 days or & 5 & 8 \\
more & & 100 \\
Sum & 100 &
\end{tabular}

remaining variables were non-significant. The most influential factors in LSS and USS were gender and amount of absence. In LSS, students with high absence from school were 1.7 times more likely to report high SP compared with those with low/no absence, and girls were 1.5 times more likely to report high SP compared with boys. In USS, students with high absence from school were 2.0 times more likely to report high SP compared with those with low/no absence, and girls were 1.5 times more likely to report high SP compared with boys.

As a test of sensitivity, the dependent variable was changed to long length of SP (defined as 8 days or more $\mathrm{SP})$, and the same set of independent variables was used. Table 5 shows ORs and $\mathrm{p}$ values (*) from two multivariate logistic regression models of factors relevant to long length of SP. Many results corresponded. There were statistically significant associations $(p<0.05)$ for 'female' and 'high absence from school' in USS. There were statistically significant associations $(p<0.05)$ for 'school motivation', 'high absence from school' and 'parents with high education' in LSS.

\section{DISCUSSION}

A majority of the students in LSS and USS reported SP in a school year. SP has not been measured in secondary schools before, so there are few relevant studies with which to compare. The finding that a majority of students reported SP was in accordance with former studies of SP among adult workers. ${ }^{3}$ 6-11

The level of SP was higher in USS compared with LSS, and $24 \%$ of students in LSS and $33 \%$ of students in USS reported high SP (four SP episodes or more). A key reason for this result could be that the amount of absence is much more important in USS than LSS. There are three points to be made.

First, previous studies have found that attendance requirements at work are strongly connected to $\mathrm{SP}^{25}$ and attendance requirements are stricter in USS than LSS. For instance, if the teacher is in no position to make an academic judgement in a subject because of high absence, the student attains the grade 1 (very low competence). The grade 1 is a passing grade for subjects in LSS, while the students must attain the grade 2 to pass a subject in USS. Eight per cent of students who started school in 2003 were still registered in USS in 2008 due to the failure to pass one or more subjects. ${ }^{26}$

Second, it is also well known that a high level of absence might negatively affect grades. ${ }^{27}$ If a student is not present, he or she might miss the explanation of crucial material, or miss homework and assignments, or fall behind and have a hard time catching up with the rest of the class. Grades from USS are often the main criteria to be admitted for further education at University/University College, and grades from USS are also important for future work applications. ${ }^{28}$ Grades do not matter that much in Norwegian LSS, since 'all students complete LSS and are admitted to their choice of education programme in USS (grades are very seldom a

Table 4 Binomial logistic regression of the factors influencing high sickness presence (four episodes or more) in Norwegian secondary school

\begin{tabular}{|c|c|c|c|c|}
\hline \multirow[b]{2}{*}{ Factors } & \multicolumn{2}{|c|}{ Lower secondary school } & \multicolumn{2}{|c|}{ Upper secondary school } \\
\hline & $\overline{\text { OR }}$ & $(95 \% \mathrm{Cl})$ & $\overline{\text { OR }}$ & $(95 \% \mathrm{Cl})$ \\
\hline Male & 1.00 & & 1.00 & \\
\hline Female & $1.45^{\star \star}$ & (1.17 to 1.95$)$ & $1.45^{\star \star}$ & (1.10 to 1.91$)$ \\
\hline Native & 1.00 & & 1.00 & \\
\hline Immigrant & 1.07 & (0.73 to 1.55$)$ & 1.31 & (0.85 to 2.01$)$ \\
\hline Parents with low education & 1.00 & & 1.00 & \\
\hline Parents with high education & 1.22 & (0.95 to 1.60$)$ & 1.08 & (0.80 to 1.43$)$ \\
\hline Working parents & 1.00 & & 1.00 & \\
\hline Non-working parents & 1.25 & (0.89 to 1.75$)$ & 1.09 & (0.76 to 1.55$)$ \\
\hline No/low absence from school & 1.00 & & 1.00 & \\
\hline High absence from school & $1.66^{\star \star}$ & (1.25 to 2.19$)$ & $1.96^{\star \star}$ & (1.47 to 2.60$)$ \\
\hline Grade point average & 0.93 & (0.78 to 1.10$)$ & 0.96 & (0.79 to 1.16$)$ \\
\hline School motivation & $0.80^{\star \star}$ & (0.69 to 0.92$)$ & 1.05 & (0.89 to 1.24$)$ \\
\hline General studies & & & 1.00 & \\
\hline Vocational studies & & & $1.36^{\star}$ & (1.00 to 1.85$)$ \\
\hline Constant & 0.82 & & 0.24 & \\
\hline
\end{tabular}


Table 5 Binomial logistic regression of the factors influencing long length of sickness presence (8 days or more) in Norwegian secondary school

\begin{tabular}{|c|c|c|c|c|}
\hline \multirow[b]{2}{*}{ Factors } & \multicolumn{2}{|c|}{ Lower secondary school } & \multicolumn{2}{|c|}{ Upper secondary school } \\
\hline & OR & $(95 \% \mathrm{Cl})$ & OR & $(95 \% \mathrm{Cl})$ \\
\hline Male & 1.00 & & 1.00 & \\
\hline Female & 1.52 & (0.92 to 2.50$)$ & $1.62^{*}$ & (1.00 to 2.63 ) \\
\hline Native & 1.00 & & 1.00 & \\
\hline Immigrant & 1.63 & (0.85 to 3.13 ) & 1.26 & (0.63 to 2.53$)$ \\
\hline Parents with low education & 1.00 & & 1.00 & \\
\hline Parents with high education & $1.69^{\star}$ & (1.00 to 2.84$)$ & 1.24 & (0.76 to 2.01$)$ \\
\hline Working parents & 1.00 & & 1.00 & \\
\hline Non-working parents & 1.42 & (0.77 to 2.62$)$ & 1.37 & (0.77 to 2.42$)$ \\
\hline No/low absence from school & 1.00 & & 1.00 & \\
\hline High absence from school & $2.16^{\star}$ & (1.04 to 4.53$)$ & $1.79^{\star}$ & (1.10 to 2.92$)$ \\
\hline Grade point average & 0.85 & (0.61 to 1.18$)$ & 0.89 & (0.64 to 1.24$)$ \\
\hline School motivation & $0.66^{\star *}$ & (0.50 to 0.86$)$ & 1.14 & (0.86 to 1.51$)$ \\
\hline General studies & & & 1.00 & \\
\hline Vocational studies & & & 1.36 & (0.81 to 2.27 ) \\
\hline Constant & 0.01 & & 0.00 & \\
\hline
\end{tabular}

criterion for admittance to education programmes in Norwegian USS)',

Third, the amount of absence is given in days and hours in the certificate for LSS and USS, and high absence could lead to lower grades for order and conduct in LSS and USS. While grades for order and conduct in LSS, in most cases, are unimportant when applying for further education or work, low grades for order and conduct from USS are very negative when applying for apprenticeships or work.

In USS, students in vocational studies reported high SP more often than students in general education. This result could have to do with different working methods in vocational studies and academic studies (more group work and laboratory work in vocational studies), and that shorter periods of work practice are obligatory in vocational studies. ${ }^{28}$ Another rationale for this result is that the registration of absence serves as a particular incentive to attend lessons for students in vocational studies. Absence may be seen as a central indicator of school engagement and ability to take responsibility, and a longitudinal study of 9000 students showed that low absence was the most important criterion when employers allocated apprenticeships for students in vocational studies. ${ }^{28}$ Absence levels are also important for work applications, and students in vocational studies begin their working careers directly from USS, while students in general studies often plan for studies at University/ University College before they are to write work applications.

The study also investigated other factors relevant to high SP in secondary school, and some results resemble those from studies among adults. A number of papers have shown positive correlations between SP and sickness absence. ${ }^{389}$ This paper about the situation in secondary school also found a strong positive correlation between absence and SP. Previous studies have found that high job satisfaction and enjoying the work is a highly reported reason for SP. ${ }^{11}{ }^{29}$ Similarly, the study in LSS displayed that motivated students enjoying what they do at school reported high SP more often than students with low motivation.

Some results of this study of SP among students do not resemble results from studies among adults. Previous studies among workers indicated no gender differences or that men more often practised $\mathrm{SP}^{1-4}$ In secondary school, however, girls more often reported high SP compared with boys. Also, previous studies among workers indicated that those with less education reported more SP than those who were highly educated, while other studies find no such correlation. ${ }^{1}{ }^{3} 8$ In LSS, however, students whose 'parents had high education' was positively associated with longer length of SP. The current study does not provide good explanations for these findings on gender and education, but these results could be related to motivation and mastery at school. Being motivated and experiencing mastery are positive reasons for $\mathrm{SP}^{11}$ and previous Norwegian studies have found that girls were more motivated and showed better mastery at secondary school compared with boys, and students with high educated parents were more motivated and experienced better school mastery than students who had parents with low educational attainment. ${ }^{24} 30$

The analyses of factors related to high SP also included migratory status, employment status and school performance. These factors did not have an impact on high SP in secondary school. An earlier study indicated that immigrant workers reported more SP than native counterparts. $^{31}$

This study had many strengths: the study included a representative sample of secondary schools (66 schools); 
the sample of students was representative and quite large (3120 students); the response rate was very high (more than 80\%); and the survey enabled simultaneous analyses of many variables of relevance to high SP.

At the same time, the use of self-reported and crosssectional data means that results from this study are tentative. First, the cross-sectional design means that it is not possible to trace causal relationships, and it is also difficult to have an in-depth discussion of the short-term and long-term consequences of high SP for students. Second, there is uncertainty over the degree of variation between students in the threshold at which they report 'should have taken sick leave'. Still, most of the studies referred to in the literature review use questions similar to those used in this study. ${ }^{1}{ }^{3} 6-1127$ Third, answers to questions about SP might have been influenced by recall bias, and this could affect the validity of the results of the survey. Five alternatives for days and four alternatives for episodes were provided to make it easier for respondents to answer questions about SP, and only $2 \%$ of the respondents did not answer. A final issue of concern is response bias, and previous studies of employees have shown that they tend to under-report their sickness absence. ${ }^{32}$ Response bias is particularly problematic in interviews face-to-face, and it is less problematic when respondents write down their answers in an anonymous survey.

The main findings from the study among students in secondary schools were that some SP during a school year may be more common than no SP, and that one in four students in LSS and one in three students in USS reported high SP. This is potentially important information since previous studies among workers have found that frequent use of SP might influence the quality and quantity of work and may also lead to future health problems. It is possible to think that frequent SP could have a negative impact on school performance and also cause future ill health, but longitudinal studies are needed to make conclusions about the consequences of high SP for students. Moreover, the study found that gender, absence from school, school motivation and education programme were associated with high SP in secondary school. The next step in research about SP in secondary schools could be to learn more about the reasons for SP among various groups of students. It would be of interest to investigate whether the reasons for SP in school are the same as the reasons for SP in working life, ${ }^{11} 29$ and whether it is positive reasons for SP (eg, enjoy school) or neutral reasons for SP (eg, do not want to burden classmates) or negative reasons for SP (eg, pressure to have a low absence percentage) that matter most in secondary schools.

Funding The data collection was supported by the Ministry of Education and Training, Ministry of Trade, Industry and Fisheries, and Ministry of Local Government and Modernisation, Norway.

Competing interests None declared.

Ethics approval Data Protection Official for Research (Norwegian Social Science Data Services).
Provenance and peer review Not commissioned; externally peer reviewed.

Data sharing statement No additional data are available.

Open Access This is an Open Access article distributed in accordance with the Creative Commons Attribution Non Commercial (CC BY-NC 4.0) license, which permits others to distribute, remix, adapt, build upon this work noncommercially, and license their derivative works on different terms, provided the original work is properly cited and the use is non-commercial. See: http:// creativecommons.org/licenses/by-nc/4.0/

\section{REFERENCES}

1. Aronsson G, Gustafsson K, Dallner M. Sick but yet at work. An empirical study of sickness presence. J Epidemiol Community Health 2000;54:502-9.

2. Johns G. Presence in the workplace: a review and research agenda. J Organ Behav 2010;31:519-42.

3. Böckerman P, Laukkanen E. What makes you work while you are sick? Evidence from a survey of workers. Eur J Public Health 2010;20:43-6.

4. Hansen CD, Andersen JH. Sick at work-a risk factor for long-term sickness absence at a later date? J Epidemiol Community Health 2009;63:397-402

5. Vingård E, Alexanderson $\mathrm{K}$, Norlund $\mathrm{A}$. Chapter 10. Sickness presence. Scand J Public Health 2004;32:216-21.

6. McKevitt C, Morgan M, Dundas R, et al. Sickness absence and 'working through' illness: a comparison of two professional groups. J Public Health Med 1997;19:295-300.

7. Rosvold EO, Bjertness E. Physicians who do not take sick leave: hazardous heroes? Scand J Public Health 2001;29:71-5.

8. Hansen CD, Andersen JH. Going ill to work-what personal circumstances, attitudes and work-related factors are associated with sickness presence? Soc Sci Med 2008;67:956-64.

9. Caverley N, Cunningham JB, MacGregor JN. Sickness presence, sickness absenteeism, and health following restructuring in a public service organization. J Manag Stud 2007;44:304-19.

10. Vroome E. Prevalence of sickness absence and 'presence'. http://eurofound.europa.eu/ewco/2006/07/NL0607019I.htm (accessed 23 Mar 2015).

11. Johansen V, Aronsson G, Marklund S. Positive and negative reasons for sickness presenteeism in Norway and Sweden: a cross-sectional survey. BMJ Open 2014;4:e004123.

12. Taloyan $M$, Aronsson $G$, Leineweber $C$, et al. Sickness presence predicts suboptimal self-rated health and sickness absence: a nationally representative study of the Swedish working population. PLOS ONE 2012;7:e44721.

13. Kivimäki M, Head J, Ferrie JE, et al. Working while ill as a risk factor for serious coronary events: the Whitehall II study. Am J Public Health 2005;95:98-102.

14. Gustafsson K, Marklund S. Consequences of sickness presence and sickness absence on health and work ability - a Swedish prospective cohort study. Int J Occup Med Environ Health 2011;24:153-65.

15. Bergström G, Bodin L, Hagberg J, et al. Sickness presence today, sickness absenteeism tomorrow? A prospective study on sickness presence and future sickness absenteeism. J Occup Environ Med 2009;51:629-38.

16. Aronsson G, Gustafsson K, Mellner C. Relationships between sickness presenteeism, sickness absenteeism and self-rated health in the Swedish working population. Int J Workplace Health Manag 2011;4:228-43.

17. Collins JJ, Baase CM, Sharda CE, et al. The assessment of chronic health conditions on work performance, absence, and total economic impact for employers. J Occup Environ Med 2005;47:547-57.

18. Hemp P. Presence: at work-but out of it. Harv Bus Rev 2004;82:49-58.

19. Lovell V. No time to be sick: why everyone suffers when workers don't have paid sick leave. Washington DC: Institute for Women's Policy Research, 2004.

20. Eagly $\mathrm{AH}$, Chaiken S. The psychology of attitudes. Fort Worth, TX: Harcourt Brace Jovanovich, 1993.

21. Kelvin P, Jarret JE. Unemployment: its social psychological effects. Cambridge: Cambridge University Press, 1985.

22. Glasman LR, Albarracin D. Forming attitudes that predict future behaviour: a meta-analysis of the attitude-behavior relation. Psychol Bull 2006;132:778-822.

23. Field A. Discovering statistics using IBM SPSS statistics. London: Sage Publications, 2013. 
24. Wendelborg C, Røe M, Skaalvik E. Analyse av Elevundersøkelsen 2011 [Analysis of the student survey 2011]. Trondheim: NTNU, 2011.

25. Johansson G, Lundberg I. Adjustment latitude and attendance requirements as determinants of sickness absence or attendance. Empirical tests of the illness flexibility model. Soc Sci Med 2004;58:1857-68.

26. Statistics Norway. Utdanning [Education]. Oslo: Statistics Norway, 2012.

27. Willms J. Student engagement at school. A sense of belonging and participation: results from Pisa 2000. Paris: OECD, 2003.

28. Markussen E, Frøseth MW, Sandberg N. Reaching for the unreachable: identifying factors predicting early school leaving and non-completion in Norwegian upper secondary education. Scand $J$ Educ Res 2011;55:225-53.
29. Marklund S, Aronsson G, Johansen V, et al. Previous sickness presence among long-term sick-listed in Norway and Sweden: a retrospective study of prevalence and self-reported reasons. Int $J$ Soc Welfare 2014. doi:10.1111/ijsw.12143

30. Raabe M. Utdanning 2009: Læringsutbytte og kompetanse [Education 2009: learning outcome and competence]. Oslo: Statistics Norway, 2009.

31. Agudelo-Suárez AA, Benavides FG, Felt E, et al. Sickness presence in Spanish-born and immigrant workers in Spain. BMC Public Health 2010;10:791.

32. van Poppel $\mathrm{M}$, de Vet $\mathrm{H}$, Koes $\mathrm{B}$, et al. Measuring sick leave: a comparison of self-reported data on sick leave and data from company records. Occup Med (Lond) 2002;52:485-90. 